Boise State University ScholarWorks

Community and Environmental Health Faculty

Department of Community and Environmental

Publications and Presentations

Health

$3-1-2004$

\title{
The Influence of Social Status on Token Women Leaders' Expectations about Leading Male- Dominated Groups
}

Theodore W. McDonald

Boise State University

Loren L. Toussaint

Idaho State University

Jennifer A. Schweiger

University of New Haven 


\title{
The Influence of Social Status on Token Women Leaders' Expectations about Leading Male-Dominated Groups
}

\author{
Theodore W. McDonald \\ Boise State University \\ Loren L. Toussaint \\ Idaho State University
}

Jennifer A. Schweiger

University of New Haven

Author Note. The authors thank Janice D. Yoder for her helpful comments on the design used in this study and on an earlier version of this manuscript and Beth Felch for her help with data collection. Address correspondence to: Theodore W. McDonald, Department of Psychology MS-1715, Boise State University, 1910 
This is an author-produced, peer-reviewed version of this article. The final publication is available at www.springerlink.com. Copyright restrictions may apply. DOI: 10.1023/B:SERS.0000018894.96308.52

University Drive, Boise, ID 83725-1715. Email:

tmcdonal@boisestate.edu 


\begin{abstract}
Prior research has shown that women report mostly negative expectations about being a gender-token in male-dominated work groups. We speculate that this is partially caused by the socially-ascribed status devaluation of women. In the present study we investigated the degree to which elevated social status may lessen negative expectations of gender-token women assigned to leadership positions. Sixty-three undergraduate women participated in one of three tokenism conditions: 1) nontoken, 2) gender-token, and 3) high-status gender-token. In all conditions participants were led to believe that they would be leading a group of men in a decision-making exercise. Leader expectations were then assessed. The results suggest that increased social status may help prevent gender-token women from developing negative expectations about interactions with maledominated work groups.
\end{abstract}

Keywords: Gender, Status, Tokenism, Leadership 


\section{The Influence of Social Status on Token Women Leaders' Expectations about Leading Male-Dominated Groups}

The past several decades have seen several remarkable transformations in the workplace in industrialized, western countries. One of the most striking changes that has occurred is the large increase in workforce participation by women (Budig, 2002; Burke, 2001; Konrad \& Cannings, 1997; Neubert, 1999). Although many women have been employed in "lower-paying, feminized occupations" (Budig, 2002, p. 258), there has been extensive interest in the small numbers of women who are employed in fields that have traditionally been populated almost exclusively by men (Floge \& Merrill, 1986; Greed, 2000; Hammond \& Mahoney, 1983; Kanter, 1977a, 1977b; Linehan, 2002; 0tt, 1989; Yoder, Adams, \& Prince, 1983). The experiences of these women, known as "tokens" (Kanter, 1977a) due to their numerical scarcity, have been carefully documented by many researchers. Social scientists have closely assessed how token women in male-dominated fields have been received by their male counterparts, as well as how they have performed and how they have felt about their organizational experiences. As we will describe in some detail, it has been found that token women tend to feel isolated, to be contrasted against their male peers, and to experience heightened pressure to perform well, both when they are members of a male-dominated work group and when they are 
tasked with leading such a group. It has also been found that token men generally do not have the same negative outcomes (in fact, they may benefit from their token status). Why token women have negative tokenism experiences, and token men often do not, is an important question with many implications for the workplace. The purpose of this article is to review the literature on token women, and then to present the results of a study that offers one possible answer as to why token women tend to experience difficulties in organizational settings: Because they are ascribed by society lower status than men.

Token Women in the Workforce

In her pioneering work on tokenism, Kanter (1977a, 1977b) described tokens as individuals who belong to a social category that constitutes less than $15 \%$ of the entire group composition. Kanter's (1977a, 1977b) research chronicled the experiences of a small number of women sales-managers at a large industrial supply company. She noted that token women managers shared several common experiences, including increased visibility, performance pressures, social isolation, and assimilation into social stereotypes. Kanter (1977b) reported that as a consequence of these common experiences, token women were more likely to: 1) have their mistakes amplified; 2) be isolated as a social outgroup; and 3) be encapsulated into roles that undermined their status. In support of Kanter's work, these results have been documented not only in women managers but also in women police 
officers (0tt, 1989), coal miners (Hammond \& Mahoney, 1983), construction workers (Greed, 2000), firefighters (Yoder \& McDonald, 1998), military cadets (Yoder, Adams, \& Prince, 1983), and law students (Spangler, Gordon, \& Pipkin, 1978). Gender Differences in Tokenism Experiences

Some early tokenism researchers maintained that being a token would result in similar consequences for women and men (e.g., Kanter, 1977a). To the contrary, much evidence suggests that for men, being a token either has no negative effects (Budig, 2002) or actually results in more positive outcomes (Fairhurst \& Snavely, 1981; Williams, 1992; Yoder \& Sinnett, 1985). Therefore, negative consequences of being a token seem to affect only women. An emerging line of research suggests that this is not only true of tokenism outcomes but also of tokenism expectations; Cohen and Swim (1995) found that gender-token women (especially when they were low in self-confidence) had more negative expectations about working with a group of men than did nontoken women, but that gender-token men and nontoken men did not differ in their expectations. Reskin (1988) accounted for women's more negative tokenism experiences in part by referring to greater gender discrimination directed toward the token women. other researchers have pointed to a wide differential in social status between women and men, such that women are ascribed much lower status by society (Fairhurst \& Snavely, 1983; Yoder, 1991; Zimmer, 1988). A unifying theme in these perspectives is the 
notion that by ascribing greater status to women, many of the negative consequences of women being gender-tokens could be reduced or eliminated.

\section{Social Status}

Before we can consider the role, if any, that social status plays in affecting tokenism processes, a brief overview of the status construct may be helpful. The role of status in determining how individuals act, think, and are perceived has been studied extensively in both social psychology and sociology. Status refers to the relative social position that accompanies certain characteristics (Baron \& Byrne, 1991). Some common status characteristics include race, age, gender, and occupation; these characteristics are said to act as "cues to individuals and are used to order their interactions with persons previously unknown to them" (Webster \& Driskell, 1985, p. 108). Webster and Driskell (1985) pointed out that status characteristics are culturally evaluated and conferred. For example, in the United States, high status characteristics include being White, male, older, and managerial, whereas low status characteristics include being a racial minority, female, younger, and non-managerial. These status characteristics, even when no attention is explicitly drawn to them, appear to be very influential variables in social processes, for example, by determining outcomes in group interactions (Berger \& Zelditch, 1985). In short, even 
when persons do not realize it, status conferred by society permeates social interactions and may play a strong role in determining leadership positions and evaluations of group members (Webster \& Driskell, 1985).

\section{Gender and Status}

That gender is an important external status characteristic is well established in both the psychological (Snodgrass, 1985, 1992; Yoder, Schleicher, \& McDonald, 1998) and sociological (Hopcroft, 2002; Ridgeway, Johnson, \& Diekema, 1994) literatures. As described above, gender, like other status characteristics, conveys information about value, competence, and worth that is culturally determined and affects subordination and superordination in groups (Webster \& Driskell, 1985). Compared to men, women are ascribed lower social status by contemporary society, and this lower status may affect their feelings and behavior in important ways. For example, Carli (1990) demonstrated that the use of tentative language by women (often considered to be a "feminine" pattern of behavior) may actually stem not from gender characteristics but rather from status; she found that men who were placed in a subordinate, and therefore lower status, role also used more tentative language. Similar findings were reported by Snodgrass (1985, 1992), who experimentally lowered the social status of men and found them to 
behave "like women" by showing greater levels of intuition and sensitivity. The tendency for women to be less influential in dyadic and group tasks may also be more due to the status that accompanies gender than to gender itself (Hopcroft, 2002). All of these results suggest that status is an important variable to measure in any social process where gender differences are found.

Gender, Status, and Tokenism

If status, rather than gender, causes a number of important feelings and behaviors in women, it follows that decrements in socially-ascribed status could account for the differential outcomes for women and men in tokenism situations. Indeed, some preliminary evidence suggests that experimentally raising the status of gender-token women may in fact reduce some of the negative consequences of tokenism. For example, Yoder and her colleagues (1998) assigned gender-token women to each of three leadership conditions: 1) simply appointed; 2) appointed and trained (i.e., provided with task-relevant information); and 3) appointed, trained, and legitimated by credible organizational personnel (the experimenters). They found that organizationally legitimating the gender-token women leaders improved group performance and reduced some of the negative consequences associated with tokenism. In effect, the researchers had elevated the social status of the leaders through training and legitimation, and it appears that this elevated social status 
reduced some of the difficulties encountered by gender-token women. This study, as well as others (e.g., Fairhurst \& Snavely, 1983; Kanter, 1977b) seems to suggest that what leads to negative consequences for gender-token women is not their gender but the socially-ascribed status that is attached to it.

Yoder and her colleagues' (1998) study is important not only because it suggests that women gender-tokens experience negative consequences in tokenism situations because they are women and because they are ascribed less status by men. It is also important because it returned the study of tokenism to women leaders, the original subject of Kanter's (1977a, 1977b) studies. The literature on women in leadership situations, particularly in male-dominated fields, has often suggested that women in management positions have different experiences than men do in terms of pay and advancement (Bielby \& Baron, 1986; Konrad \& Cannings, 1997), social support (Burke, 2001; Rothstein, Burke, \& Bristor, 2001), and role strain (Budig \& England, 2001). It is possible that women have these different experiences because they utilize different leadership styles in management roles. Certainly, some researchers have maintained that women and men use different leadership styles (e.g., Grant, 1988; Loden, 1985; Rosener, 1995), however, others have pointed out that these differences are generally quite small and have little practical significance (Powell, 1997). Thus, what accounts for the experiential differences reported for token women leaders may be 
something other than leadership styles, and Yoder and her colleagues' (1998) status explanation seems plausible.

If the negative consequences that women leaders experience in tokenism situations can be accounted for by socially-ascribed status rather than by gender, perhaps the same is true about gender-token women leaders' expectancies about leading a group. Past studies on gender-token women's expectancies (e.g., Cohen \& Swim, 1995) clearly show that gender-token women have more negative expectations than do non-token women. Perhaps elevating the social status of gender-token women would also alleviate some of these negative expectations. These questions provided the impetus for the present study.

The Present Study

The purpose of the present study was to extend the literature on the expectations of gender-token leaders. In developing this study, we used two previous pieces of research to guide our methods and hypotheses. We borrowed heavily from the methodology of Cohen and Swim's (1995) expectations study, which involved leading participants to believe that they would be working with several other people on a group task (solving analytical problems); the gender composition of the groups in which the participants thought that they would be working was varied to create nontoken and gender-token conditions. After manipulating the gender composition of the purported groups (there was no actual group with whom to meet, and no group task 
was ever performed), Cohen and Swim (1995) simply measured participant expectations about their group experience (across a range of expected outcomes, including standing out in the group, being an effective group member, and desiring to change to another group). This procedure was found to be a simple and effective method to manipulate the gender composition of a "group" and measure expectations about being part of it. We used several key aspects of their procedure and tailored it to fit the specifics of our own study.

The present study was also influenced by the theoretical underpinnings of Yoder and her colleagues' (1998) study, as we attempted to employ a structural/organizational strategy (increasing social status) with the intent to enhance expectations for gender-token women who work in male-dominated fields. The present study is unique in that we examined the extent to which increased social status impacted gender tokens' expectations about a group leadership task. In so doing, we expand on the relatively underdeveloped literature on tokenism expectations (as opposed to actual experiences). We also examine the expectations of gender-token women who are placed in a leadership role, where the effects of tokenism may be more pronounced (Yoder et al., 1998). We manipulated social status using age and education, two empirically-validated status characteristics (Ridgeway et al., 1994). We randomly assigned 21 women to each of three tokenism conditions: 1) nontoken; 2) 
gender-token; and 3) high-status gender-token. We utilized 10 items (modeled after those used by Cohen and Swim (1995)) to measure leader expectations.

We hypothesized that gender-token women would report more negative expectations on all measures concerning the upcoming group interaction than would nontoken women. We further hypothesized that status would reduce some negative expectations such that high-status gender-token women would be more similar to nontoken women than to gender-token women in their expectations of performance pressure, anxiety, comfort, confidence, and effectiveness. In addition, we predicted that the nontoken leaders would report lower expectations than would both groups of gender-token leaders on measures that captured simple gender differences in leader and group member characteristics (i.e., measures that highlighted the woman as different from the men). These measures included expectations for desiring to change groups, desiring to change the gender composition of the group, being stereotyped, stereotyping others, and standing out.

Method

\section{Participants}

Sixty-three undergraduate women from a large midwestern university participated in the study for supplementary course credit. ${ }^{1}$ To control the effects of other external status characteristics, only data from white women 18-24 years old $(M=$ 19.50, $\underline{s d}=1.20$ ) were included in the analysis. ${ }^{2}$ 
Design

The design used was a three-group between-subjects design, with 21 women assigned to each condition. Nontokens expected to lead a group composed entirely of six women. Gender-tokens expected to lead a group of six men similar to themselves in age and education. High-status gender-tokens expected to lead a group of six high-school boys. Thus, women in the third condition were substantially higher than the dominant group members on two empirically validated status characteristics: age and level of education (Ridgeway et al., 1994).

Materials

Participant personal profiles. These profiles were adapted from those employed by Cohen and Swim (1995). Participants recorded their first names, gender, hobbies, career goals, and perceived strengths and weaknesses. Personal profiles also doubled as sign-up sheets for participation.

Personal profiles of the purported group members. Six personal profiles were designed to describe the six purported members of each group. Three different versions of personal profile materials were created. The first version consisted of female group members who ranged in age from 18 to 22 years old and who were enrolled as college undergraduates. The second version was identical to the first in all respects except that the names on the profiles were masculine. The third version was identical to the second except that the students were described 
as high school freshmen who ranged in age from 13 to 14 years old. ${ }^{3}$ The names of purported group members in all three groups were selected from a listing of stimulus person names that do not induce gender or age bias (e.g., the names for men were common names for males but were neither "too masculine" or "too feminine", and were not stereotypically older or younger persons' names) (Kasof, 1993).

Analytical problems. Three sample problems used in this study were selected from the 16 gender-neutral problems used by Cohen and Swim (1995). The original source of these analytical problems is the Graduate Record Examination (GRE) test guide (Martinson \& Crocetti, 1987).

Manipulation check. To ensure that the participants were aware of the status characteristics of the members of their groups, each participant was asked to write on a piece of paper the seven purported group members' (including her own ) names, ages, and levels of education. To insure that no initial differences existed in the participants' expectations about the problem-solving task, a single item assessed confidence about being able to complete the analytical problems. Materials. Each participant completed a leader expectation questionnaire to rate her: 1) desire to change to a different group; 2) desire to change the gender composition of her group; 3) expectation of being stereotyped by virtue of her gender; 4) expectation of stereotyping her group members by virtue of their 
gender; 5) expectation of standing out; 6 ) feelings of performance pressure; 7) feelings of anxiety; 8) feelings of comfort; 9) feelings of confidence about leading; and 10) expectation about being an effective leader. Each of these expectations was assessed by a single item included on the questionnaire. Responses were made on a 7-point Likert-type scale.

Procedure

Participants were recruited from introductory psychology and other large, survey classes for a study of group decision-making processes. Each participant arrived at the laboratory individually and was greeted by a male and female experimenter in front of two adjacent rooms. On one of the two doors a sign was posted that read "Group Members Only." Clearly visible inside this room were a number of desks arranged in a circle. On each desk were papers and a pencil that were presumably for the advertised decision-making task. On the second door, a posted sign read "Group Leaders Only." The experimenters verified the name of the participant and informed her that she had been randomly selected to be the leader of the group. It was then explained that she had been asked to report earlier than the other members of her group.

Each participant was ushered into the room purportedly intended for group leaders. The experimenters explained that the study was designed to assess the performance of groups whose 
members knew something about one another compared to groups whose members knew nothing about each other. The participants were all told that they would be leading the type of group whose members knew something about one another prior to working on a decisionmaking task. Each participant was then given one of three prepared packets of "personal profiles" of six purported group members. The personal profile sheets were identical to that which each participant herself had completed when initially recruited to take part in the experiment. Each profile packet contained identical information except for the names of the purported group members. All purported group members were female in the nontoken condition and male in both the gender token and high-status gender token conditions. Age of purported group members was the same in both the nontoken and gender-token conditions and 4-9 years younger in the high-status gender-token conditions. Education level of the purported group members was college-level in the nontoken and gender-token conditions and high school freshmen-level in the high-status gender-token condition.

Each participant was informed that the group would work on a decision-making task that involved completing 16 analytical problems, and she was given three sample problems to examine. She was then told to peruse the personal profiles of her purported group members while she waited for the other members of the group to arrive. She was asked to complete a group member 
sheet that required her to write the first name, age, and level of education of each member of the group, including herself. This sheet was a manipulation check to ensure that each participant was aware of the gender composition of the group and of the salient external status characteristics of the purported group members. Just prior to when she believed that she would join the group, each participant was given a leader expectation questionnaire that queried her about the dependent measures. After the questionnaire was completed, each participant was informed that the experiment was over and that no group meeting would take place. Each participant was then debriefed, informed about why deception had been used, and entrusted not to discuss the study with other potential participants.

Statistical Analyses

Consistent with our hypotheses, we conducted planned contrasts on all leader expectation variables. We tested differences between high-status gender-tokens and nontokens, and then compared these combined groups to gender-tokens on measures of: 1) performance pressure; 2) anxiety; 3) comfort; 4) confidence; and 5) effectiveness. We also examined differences between the two gender-token groups, and then compared these combined groups to nontokens on measures of: 1) desiring to change groups; 2) desiring to the change the gender composition of the group; 3) being stereotyped; 4) stereotyping others; and 5) standing out. All comparisons were made using t-tests. 
Results

As expected, we found no differences between high-status gender-tokens and nontokens on measures of performance pressure, anxiety, comfort, confidence, and effectiveness. However, the two combined groups differed significantly from gender-tokens on each of these measures (see Table 1). As expected, we found no differences between high-status gender-tokens and gender-tokens on measures of desiring to change groups, being stereotyped, stereotyping others, and standing out. However, the combined groups differed significantly from nontokens on these measures (see Table 2). There were no differences on the measure of desiring to change the gender composition of the group. Manipulation Check

Visual inspection of the first manipulation check confirmed that all participants correctly noted the names, ages, and levels of education of the purported members of their groups. The second check showed that leaders among the three groups did not differ in how ably they thought they could complete the analytic problems, $F(2,60)=.61, p=.55$.

\section{Discussion}

In this experiment, we investigated how increasing social status for gender-token women leaders may help to minimize negative expectations that women tokens have been found to form. An understanding of the role that social status plays in determining how gender-token women feel about leading groups of 
men is important in several regards. First, as prior researchers have noted, gender-token women leaders may have negative expectations and experiences not because they are women, but rather because they are ascribed less status than men (Fairhurst \& Snavely, 1983; Hopcroft, 2002; Yoder et al., 1998). Second, to maximize women's satisfaction and work performance, organizations may have to play a more active role in raising the status of gender-token women in leadership positions, particularly when their subordinates are men.

As expected, we found that both gender-token leaders and high-status gender-token leaders differed from nontoken leaders on most of those expectations that were influenced by simple differences in group member (gender) characteristics. Both gender-token leaders and high-status gender-token leaders expected to desire to change groups, to be stereotyped by virtue of their gender, to stereotype others, and to stand out more than did nontoken women. It is interesting that high-status gendertokens and gender-tokens did not express a greater desire to change the gender composition of their groups than did nontoken women .

Our hypothesis that status would abate leaders' negative expectations regarding leading their groups was also upheld. We expected high-status gender-token leaders and nontoken leaders to score similarly on expectation measures of performance pressure, anxiety, comfort, confidence, and effectiveness. Further, 
relative to nontokens and high-status gender-tokens, we hypothesized that gender-tokens would differ significantly on these measures. This was true for every expectation variable. Elevating the social status of gender-token women thus seems to have ameliorated many negative expectations that are commonly found in this population (Cohen \& Swim, 1995; Yoder et al., 1998).

Clearly, our status manipulation was effective in reducing many negative expectations. Exactly how the status manipulation had its effect is unclear in this study and can only be thoroughly addressed in future research. Nevertheless, we offer two suggestions for how status might have reduced negative expectations. First, we suggest that by inducing women leaders to believe that they would be leading male adolescents who were younger and less educated than they, we effectively leveled the social status of all members of the group. Second, we invoke the relational demography hypothesis to provide an additional explanation of our findings. According to the relational demography hypothesis the comparative similarity/dissimilarity of multiple demographic characteristics of group members has a powerful effect on members' perceptions and behaviors (Tsui \& 0'Reilly, 1989). A group member may be different from others on a number of important characteristics (e.g., age, education, experience), and, thus, experience negative perceptions and behaviors that result from being more socially distant. However, 
Tsui and O'Reilly (1989) have suggested that in some instances being different on a number of relational demographics can lead to positive rather than negative effects. Leaders may feel more confident and powerful in situations where subordinates are younger, less educated, and less experienced than superiors. In our study, the relational demographics were aligned in such a fashion that being a low status woman may have been offset by being older and more educated.

The similarity between the findings in the present study and those reported by Cohen and Swim (1995), who found that gendertoken women only had negative expectations about being a token when their self-confidence had been experimentally lowered, suggests that social status and self-confidence may be two related factors that affect tokenism outcomes. Both elevated social status and heightened self-confidence helped token women to avoid developing negative expectations. It may be the case that by elevating social status we simply raised gender-tokens' self-confidence. In fact, it is possible that heightened selfconfidence rather than high social status led to diminished negative expectations. We argue that, despite overlap in the constructs, they are not identical and are developed or conferred, at least in part, through different mechanisms. For example, it is quite possible to have high self-confidence and low social status. Conversely, one might have low selfconfidence and high social status. Although our findings are 
similar to those of Cohen and Swim's (1995), they are by no means identical. High self-confidence has not been shown to lead to increased comfort, decreased anxiety, or decreased performance pressure, but we did find these effects in high-status tokens. These conceptual and empirical similarities and differences are intriguing. Further work seems warranted to determine the separate and combined effects of these constructs.

It is also possible to argue that merely placing women in leadership positions elevates their social status. In other words, by placing women participants into a typically masculine role we may have also elevated their status. Perhaps simply being in a leadership position leads to greater expectations of comfort, confidence, effectiveness, and the like. There are two reasons why we believe that this is not the case. First, Yoder and her colleagues (1998) found that gender-token women who were simply appointed to lead a group of men experienced the same deficits as gender-token women who were not leaders. Second, gender-token leaders in the present study did not appear to feel empowered by high social status. These women reported more negative expectations than both nontoken and high-status gendertoken women. We maintain that simply appointing women to leadership roles does not give them high status (although it gives them higher status than they would otherwise have had). More ambitious status manipulations are necessary to help gendertoken women leaders to avoid negative expectations and outcomes. 
If gender-token women in organizations expect problems leading men, then these expectations are ultimately detrimental to women's career aspirations. Many high paying and prestigious jobs are skewed heavily in favor of men (England, 1992; England, Reid, \& Kilbourne, 1996). It is quite possible that knowledge of these ratios and fear of negative consequences of token status reduce the likelihood that women aspire to those positions. Organizations and institutions that are interested in helping women to access male-dominated professions may consider methods of status enhancements for proportionately-scarce women. Although the status-enhancing manipulation used in the present study is not feasible in the workplace, there are more practical methods. For instance, the program of task-related training and organizational legitimation developed by Yoder and her colleagues (1998) is one alternative that may be used in almost any workgroup setting. This method of status enhancement requires that token women leaders be specifically trained on group tasks, and (very important) that group members are made aware of the leader's training and qualifications. Other methods of empowerment might include the provision of social support to women leaders from persons in high positions of organizational status and power (Rothstein et al., 2001) and implementing support to help women leaders balance responsibilities between family and job (Al-Rasheed \& Dawlah, 2002). 
The present study provides evidence that social status influences tokenism expectations. However, it is important to note that our sample included college students from a large midwestern university located in a metropolitan area. Given the unrepresentative nature of college student samples, caution should be used in generalizing these findings to the workforce or other broad populations. Nonetheless, we believe that enhancing the status of women can benefit them personally and professionally. Enhanced social status can open otherwise closed doors and provide opportunities for leadership that might otherwise be avoided. 


\section{References}

Al-Rasheed, A., \& Dawlah, J. A. (2002). Factors affecting women's attitudes toward obstacles facing their career advancement and their empowering strategies in Jordanian business organizations. Administrative Sciences, 29, 48-72.

Baron, R. A., \& Byrne, D. (1991). Social psychology. Boston, MA: Allyn \& Bacon.

Berger, J., \& Zelditch, M. (Eds.). (1985). Status, rewards, and influence. San Francisco: Jossey-Bass.

Bielby, W., \& Baron, J. (1986). Women and men at work: Sex segregation and statistical discrimination. American Journal of Sociology, 91, 759-799.

Budig, M. J. (2002). Male advantage and the gender composition of jobs: Who rides the glass escalator? Social Problems, $49,258-277$.

Budig, M. J., \& England, P. (2001). The wage penalty for motherhood. American Sociological Review, 66, 204-225.

Burke, R. J. (2001). Organizational values, work experiences, and satisfactions among managerial and professional women. Journal of Management Development, 20, 346-353.

Carli, L. (1990). Gender, language, and influence. Journal of Personality and Social Psychology, 59, 941-951.

Cohen, L. L., \& Swim, J. K. (1995). The differential impact of gender ratios on women and men: Tokenism, self- 
confidence, and expectations. Personality and Social Psychology Bulletin, 21, 876-883.

England, P. (1992). Comparable worth: Theories and evidence. Hawthorne, NY: Aldine de Gruyter.

England, P., Reid, L. L., \& Kilbourne, B. S. (1996). The effect of the sex composition of jobs on starting wages in an organization: Findings from the NLSY. Demography, 33, 511521.

Fairhurst, G. T., \& Snavely, B. K. (1981). An examination of the communication between high status tokens and their dominant colleagues: Kanter's theory reexamined. Academy of Management Journal, 26, 353-361.

Fairhurst, G. T., \& Snavely, B. K. (1983). Majority and token minority group relationships: Power acquisition and communication. Academy of Management Review, 8, 292-300. Floge, L., \& Merrill, D. M. (1986). Tokenism reconsidered: Male nurses and female physicians in a hospital setting. Social Forces, 64, 925-947.

Grant, J. (1988). Women as managers: What they can offer to organizations. Organizational Dynamics, 16, 56-63.

Greed, C. (2000). Women in the construction professions: Achieving critical mass. Gender, Work, \& Organization, 7, 181-196.

Hammond, J., \& Mahoney, C. (1983). Reward-cost balancing among women coal miners. Sex Roles, 9, 17-29. 
Hopcroft, R. (2002). Is gender still a status characteristic?

Current Research in Social Psychology.

http://Www . uiowa. edu/grpproc/crisp/7.20.htm .

Kanter, R. M. (1977a). Men and women of the corporation. New York: Basic Books.

Kanter, R. M. (1977b). Some effects of proportions on group

life: Skewed sex ratios and responses to token women. American Journal of Sociology, 82, 965-990.

Kasof, J. (1993). Sex bias in the names of stimulus persons. Psychological Bulletin, 113, 140-163.

Konrad, A. M., \& Cannings, K. (1997). The effects of gender role congruence and statistical discrimination on managerial advancement. Human Relations, 50, 1305-1313.

Linehan, M. (2002). Senior female international managers:

Empirical evidence from Western Europe [Special issue: Women in global business]. International Journal of Human Resources Management, 13, 802-814.

Loden, M. (1985). Feminine leadership, or how to succeed in business without being one of the boys. New York: Times Books.

Martinson, T. H., \& Crocetti, G. (Eds.). (1987). Graduate Record Examination general text (2nd ed.). New York: Prentice Hall.

ott, E. M. (1989). The effects of the male-female ratio at 
work. Psychology of Women Quarterly, 13, 41-57.

Powell, G. (1997). Leadership and gender: Vive la difference? In M. R. Walsh (Ed.), Women, men, \& gender: Ongoing debates (pp. 298-305). New Haven, CT: Yale University Press.

Reskin, B. (1988). Bringing men back in: Sex differentiation and the devaluation of women's work. Gender \& Society, 2, $58-81$.

Ridgeway, C. L., Johnson, C., \& Diekema, D. (1994). External status, legitimacy, and compliance in male and female groups. Social Forces, 72, 1051-1077.

Rosener, J. B. (1995). America's competitive secret: Utilizing women as a management strategy. New York: 0xford University Press.

Rothstein, M. G., Burke, R. J., \& Bristor, J. M. (2001). Structural characteristics and support benefits in the interpersonal networks of women and men in management. International Journal of Organizational Analysis, 9, 4-25.

Snodgrass, S. E. (1985). Women's intuition: The effect of subordinate role on interpersonal sensitivity. Journal of Personality and Social Psychology, 49, 146-155.

Snodgrass, S. E. (1992). Further effects of role versus gender on interpersonal sensitivity. Journal of Personality and Social Psychology, 62, 154-158. 
Spangler, E., Gordon, M., \& Pipkin, R. (1978). Token women: An empirical test of Kanter's hypothesis. American Journal of Sociology, 84, 160-170.

Tsui, A. S., \& 0’Reilly III, C. A. (1989). Beyond simple demographic effects: The importance of relational demography in superior-subordinate dyads. Academy of Management Journal, 32, 402-423.

Webster, M., \& Driskell, D. G. (1985). Status generalization. In J. Berger \& M. Zelditch (Eds.), Status, rewards, and influence. San Francisco: Jossey-Bass.

Williams, C. L. (1992). The glass escalator: Hidden advantages for men in "female" professions. Social Problems, 39, 253267.

Yoder, J. D. (1991). Rethinking tokenism: Looking beyond numbers. Gender \& Society, 5, 178-192.

Yoder, J. D., Adams, J., \& Prince, H. (1983). The price of a token. Journal of Political and Military Sociology, 11, $269-276$.

Yoder, J. D., \& McDonald, T. W. (1998). Measuring sexist discrimination in the workplace: Support for the validity of the Schedule of Sexist Events. Psychology of Women Quarterly, 22, 487-491.

Yoder, J. D., \& Sinnett, J. (1985). Is it all in the numbers? A case study of tokenism. Psychology of Women 
Quarterly, 9, 413-418.

Yoder, J. D., Schleicher, T. S., \& McDonald, T. W. (1998).

Empowering token women leaders: The importance of

organizationally legitimated credibility. Psychology of

Women Quarterly, 22, 209-222.

Zimmer, L. (1988). Tokenism and women in the workplace: The

limits of gender-neutral theory. Social Problems, 35, $64-76$. 


\section{Footnotes}

1 During debriefing, one participant reported having knowledge of the deception used in the experiment, and another indicated that she believed the experiment was focused on the influence of gender ratios; the data from these two participants were excluded from the final analysis, and two new participants were added. ${ }^{2}$ Although exclusion of members of other racial, ethnic, and age groups is not desirable and limits the external validity of the experiment, precise control of status characteristics was necessary to ensure the efficacy of our status manipulations. 3 To make the notion of high-school boys on a university campus more believable, the participants in the high-status gender-token condition were told that a number of high-school students participated in university projects on an exchange basis. 
Table 1

Means and Standard Deviations for Women Leaders' Expectation of Performance Pressure, Anxiety, Comfort, Confidence, and Effectiveness by Condition

\begin{tabular}{|c|c|c|c|c|c|c|}
\hline \multicolumn{7}{|c|}{ Contrast 1 Contrast 2} \\
\hline \multirow[t]{2}{*}{ Performance pressure } & 3.29 & 4.43 & 3.62 & 0.70 & 2.37 & * \\
\hline & 1.55 & 1.66 & 1.40 & & & \\
\hline \multirow[t]{2}{*}{ Anxiety } & 2.76 & 4.38 & 3.33 & 1.17 & 3.14 & ** \\
\hline & 1.58 & 1.57 & 1.62 & & & \\
\hline \multirow[t]{2}{*}{ Comfortable } & 5.29 & 4.19 & 5.14 & 0.33 & 2.75 & ** \\
\hline & 1.64 & 1.40 & 1.06 & & & \\
\hline \multirow[t]{2}{*}{ Confidence } & 5.38 & 4.76 & 5.71 & 0.87 & 2.36 & * \\
\hline & 1.47 & 1.34 & $\odot .85$ & & & \\
\hline \multirow[t]{2}{*}{ Effectiveness } & 5.19 & 4.81 & 5.67 & 1.36 & $2 . \odot 4$ & * \\
\hline & 1.17 & 1.29 & 0.91 & & & \\
\hline \multicolumn{7}{|c|}{$\begin{array}{l}\text { Note. Nontoken (NT), Gender-token (GT), High-status gender-token } \\
\text { (HSGT). Contrast } 1 \text { tests difference between high-status gender- } \\
\text { tokens and nontokens. Contrast } 2 \text { tests difference between } \\
\text { combined high-status gender-tokens and nontokens versus gender- }\end{array}$} \\
\hline
\end{tabular}


Table 2

Means and Standard Deviations for Women Leaders' Expectation to Change Groups, Change Group Composition, Be Stereotyped, Stereotype others, and stand out by Condition

\begin{tabular}{|c|c|c|c|c|c|c|}
\hline Expectation & NT & GT & HSGT & Contrast 1 & 1 Contrast 2 & $p$ \\
\hline \multirow[t]{2}{*}{ Change group } & 1.90 & 2.81 & 3.05 & 0.51 & 2.51 & * \\
\hline & 1.51 & 1.67 & 1.40 & & & \\
\hline \multirow[t]{2}{*}{ Change composition } & 4.48 & 4.95 & 5.05 & 0.17 & 1.09 & \\
\hline & 1.81 & 1.83 & 1.77 & & & \\
\hline \multirow[t]{2}{*}{ Being stereotyped } & 2.48 & 5.05 & 5.19 & 0.30 & 6.35 & *** \\
\hline & 1.33 & 1.80 & 1.50 & & & \\
\hline \multirow[t]{2}{*}{ Stereotyping others } & 2.57 & 3.95 & 3.38 & 1.15 & 2.53 & ** \\
\hline & 1.81 & 1.62 & 1.40 & & & \\
\hline \multirow[t]{2}{*}{ Standing out } & 4.14 & 5.86 & 6.52 & 1.76 & 6.24 & *** \\
\hline & 1.35 & 1.24 & 1.08 & & & \\
\hline \multicolumn{7}{|c|}{$\begin{array}{l}\text { Note. Nontoken (NT), Gender-token (GT), High-status gender-token } \\
\text { (HSGT). Contrast } 1 \text { tests difference between high-status gender- } \\
\text { tokens and gender-tokens. Contrast } 2 \text { tests difference between } \\
\text { combined high-status gender-tokens and gender-tokens versus }\end{array}$} \\
\hline
\end{tabular}

